\title{
Clinical Supervision and Non-Technical Professional Development Skills in the Context of Patient Safety-The Views of Nurse Specialist Students
}

\section{Anne Lind Jølstad, Eva Røed Røsnæs, Anne Lyberg, Elisabeth Severinsson}

The Centre for Women's, Family and Child Health, Department of Nursing and Health Sciences, Faculty of Health and Social Sciences, University College of Southeast Norway, Kongsberg, Norway

Email: Anne.Jolstad@usn.no

How to cite this paper: Jølstad, A.L., Røsnæs, E.R., Lyberg, A. and Severinsson, E. (2017) Clinical Supervision and NonTechnical Professional Development Skills in the Context of Patient Safety-The Views of Nurse Specialist Students. Open Journal of Nursing, 7, 253-267. https://doi.org/10.4236/ojn.2017.72021

Received: January 12, 2017

Accepted: February 21, 2017

Published: February 24, 2017

Copyright $\odot 2017$ by authors and Scientific Research Publishing Inc. This work is licensed under the Creative Commons Attribution International License (CC BY 4.0).

http://creativecommons.org/licenses/by/4.0/

\begin{abstract}
The aim of the study was to evaluate nurse specialist students' views of clinical supervision (CS) and its influence on their professional competence development. An additional aim was to interpret the results and link them to nontechnical skills and Patient Safety (PS) topics. The research question was: What are the benefits of clinical supervision focusing on non-technical skills in the area of PS? A cross-sectional study of 46 nurse specialist students was conducted by means of questionnaires and exploratory factor analysis. Factors that influenced the nurse specialist students' competencies were: interpersonal, professional and communication skills in addition to awareness of ethical skills, the importance of teamwork and the benefit of involving patients and their family members in safe care. The results were linked to non-technical skills and PS competencies. Clinical supervision is crucial for the development of non-technical skills and PS competencies among nurse specialist students. However, finding time to reflect and learn from the supervision was reported to be a problem. Over half of the students stated they did not have enough time for supervision. Thus, there is a potential for quality improvement. We recommend that universities should provide formal educational programmes for supervisors focusing on the professional development of students, especially in the area of non-technical skills. In conclusion, CS should be prioritised by management and clinical leaders as it enhances PS.
\end{abstract}

\section{Keywords}

Clinical Supervision, Non-Technical Skills, Nurse Specialist Students, Patient Safety, Professional Development 


\section{Introduction}

This study focuses on nurse specialist students (NSS) in the final phase of their postgraduate education in surgical, oncology, anaesthesia and intensive care nursing. The education comprises both a theoretical and a clinical part. Clinical supervision (CS) and systematic reflection on clinical experiences constitute an important component of the education. Supervisors are in a unique position to facilitate learning processes and promote the students' professional growth and identity building as specialist nurses [1] [2]. However, many clinical nurse supervisors in Norway have no formal qualifications or training for supervision. The supervisor's role is significant for the quality of supervision and a systematic structure enhances the students' professional development, leading to positive outcomes in terms of quality and patient safety (PS) [3]. Empirical research has focused on different models of supervision, effectiveness and quality of care as well as on ethical issues [3]. There are several definitions of CS and Lyth [4] underlined the difficulty of clarifying the concept, as nursing practice varies. An article by Proctor [5] identified three components of supervision: normative (standard setting), formative (development) and restorative (support), which have been adopted by the nursing profession as key elements in the CS literature [6]. These three components have stood the test of time, thus the purpose and content of CS encompasses one or a combination of the following: a learning, supportive and monitoring process [6]. In this paper, CS is defined as a pedagogical human development process, in which the participants raise questions, explore, explain and systematize care experiences from a perspective that is considered holistic in the professional context [7].

PS is the cornerstone of high quality healthcare [8]. Systematic development of PS is necessary as poor quality care causes human suffering [9]. Much of the work defining PS and practices that prevent harm has focused on negative care outcomes, such as mortality and morbidity [8]. Patient safety culture is a subset of the organizational culture relating specifically to the values and beliefs concerning PS [10]. Mustard [11] (p. 112) defined the patient safety culture as "a product of social learning, ways of thinking and behaving that are shared and that work to meet the primary objective of patient safety". Implementation of PS requires evidence-based knowledge, professional staff and financial resources [12]. Thus, the quality of care is dependent on nurses' professional competence and the use of the best evidence in practice [13].

Work remains to be done in evaluating how PS competencies can be learnt and how knowledge, skills and attitudes that enhance PS can be developed [14] [15]. According to Sullivan et al. [16], a major national initiative in the US, Quality and Safety Education for Nurses (QSEN), attempted to define competencies for nursing students. The primary goal was to address the challenge of providing future nurses with the necessary knowledge, skills and attitudes to continuously improve the quality and safety of the healthcare systems in which they work [17]. The competencies are supported by The WHO [18] safety curriculum guidelines and include patient-centred care, teamwork and collabora- 
tion, evidence-based practice, quality improvement and safety, as well as the use of informatics. Altmiller [1] demonstrated how the competencies can be transferred to a nurse specialist role. Patients undergoing surgery are at the highest risk of harm and adverse healthcare events [19]. A reason for this is the surgery team, which often consists of two surgical nurses, an anaesthesia nurse, an anaesthesia physician and at least one operating physician. Each professional must have the competence to manage her/his own professional work and know how to coordinate it with that of the other team members [20]. As lack of coordination and cooperation in the operating theatre poses a threat to PS, teamwork competence must be developed during the NSS education.

Flin et al. [21] (p. 1) define non-technical skills as "the cognitive, social and personal resource skills that complement technical skills, and contribute to safe and efficient task performance". Rasmussen et al. [22] identified the following set of non-technical skills for surgical nurses: 1) Cognitive skills, which involve making use of knowledge and experiences, understanding the situation, perceiving changes and considering measures; 2) Cooperative skills, which include understanding the division of work in the team, adjusting one's own duties to those of the other team members and ability to communicate; 3) Self-management skills, which encompass exhibiting self-control, a professional manner and working under time pressure; 4) Ethical skills, examples of which are showing respect, contributing to a positive work climate and having a caring attitude towards patients and colleagues.

We focused on the influence of CS on professional development related to PS. In addition, we would like to compare the results of this study with the evidence of PS competencies as recommended by the QSEN (2003), [21], Flin et al. [22] Rasmussen et al. [22] and Patient Safety Topics as identified by Jha et al. [15]. A PS curriculum strengthens the necessary attitudes, behaviours and skills, making it a prerequisite for healthcare education and training to enhance PS [23]. This underlines the importance of evaluating clinical training and the way in which CS influences nursing practice.

\section{Aim}

The aim of the study was to evaluate nurse specialist students' views of CS and its influence on their professional competence development. An additional aim was to interpret the results and link them to non-technical skills and Patient Safety (PS) topics. The research question was: What are the benefits of CS focusing on non-technical skills in the area of PS?

\section{Methods}

\subsection{Design}

This study had a descriptive-correlational design [24]. Data were collected from NSS in Norway, using a package of instruments to measure the influence of CS, the students' views on the benefit of supervision, as well as their perceptions of the involvement of patients and family members in safe care. 


\subsection{Sample}

All registered NSS $(\mathrm{n}=56)$ taking part in the Postgraduate education at the University College in June 2015 were eligible to participate in the study, which included four healthcare contexts. The questionnaire was distributed to the participants at the end of their clinical placements during the final semester of their education. In total, 46 NSS (8 anaesthesia, 11 intensive care, 14 operation/surgical and 13 oncological care) completed and returned the questionnaire to the first author. The response rate was $82 \%$. The characteristics of the participants are presented in Table 1.

\subsection{Measures}

The questionnaire included three instruments: the Manchester Clinical Supervision Scale (MCSS) [25] [26], the Effects of Supervision Scale (ESS), [7] designed to measure nurses' views of the effectiveness of CS and the Focus on Empowerment Supervision Scale (FESS) [27], that illuminates user involvement, nursing documentation and the influence of supervision, in addition to providing demographic data.

\subsubsection{The Manchester Clinical Supervision Scale}

The participants were asked to rate 36 items divided into seven factors; Trust/ Rapport, Supervisor advice/support, Improved care/skills, Importance value of CS, Finding time, Personal issues and Reflection (MCSS) [25] [26]. The response alternatives for items such as "Clinical supervision improves the quality of care I give to my patients" and "Supervision gives me time to reflect" ranged from 1 (strongly disagree) to 5 (strongly agree). In a previous study the reliability score

Table 1. Demographic characteristics of the students.

\begin{tabular}{lc}
\hline Sample characteristics & $\mathrm{N}=46^{*}$ \\
\hline Age, years, med (q1 - q3) & $36.5(31.0-39.3)$ \\
Female gender & $42(91.3 \%)$ \\
Previous work experience, years, med (q1 - q3) & $10.0(6.0-13.3)$ \\
Speciality, No (\%) & \\
Anaesthesia & $8(17.4 \%)$ \\
Intensive care & $11(23.9 \%)$ \\
Operation/Surgery & $14(30.4 \%)$ \\
Oncology & $13(28.3 \%)$ \\
Female supervisor & $42(93.3 \%)$ \\
Supervisor education & \\
No & $7(15.2 \%)$ \\
Yes & $11(23.9 \%)$ \\
Did not know & $28(60.9 \%)$ \\
\hline
\end{tabular}

${ }^{*}$ Due to internal missing data, $\mathrm{N}$ varies between 44 and 46. 
for the full-item scale was $0.86[26]$.

\subsubsection{The Effects of Supervision Scale}

The 25 items from the Effects of Supervision Scale (ESS) were used to measure what the students had learnt in CS. Examples of items are: "I can deal with difficult caring situations", "I realize when I need help from others" and "I can plan more easily together with the patient" [7]. The ESS comprises three sub-scales: Interprofessional skills, Professional skills and Communication skills with responses indicated on a 4-point scale ranging from strongly disagree to strongly agree. The known reliability is 0.96 [28].

\subsubsection{The Focus on Empowerment Supervision Scale}

The Focus on Empowerment Supervision Scale (FESS) is a 24 item instrument that measures nurses' perceptions of empowerment, documentation, the influence of CS, involving users by preserving their integrity and enabling the participation of the patient and her/his family in decision-making [27] [29]. The participants were asked to rate items on a Likert scale with scores ranging from 1 (strongly disagree) to 4 (strongly agree). Examples of items of pertaining to perceptions of the influence of supervision, documentation and user involvement in the nursing process are: "I am satisfied with the learning situation at my clinical practicum" and "I cooperate with the patient in all parts of the problem-solving process”. The two factor solution yielded a Cronbach's alpha score of 0.84 [27].

\subsection{Data Analysis}

Descriptive and correlational analyses were employed in the analytic procedures. The statistical analyses were conducted using the Statistical Package for the Social Sciences (SPSS) PC-version 20.0 for Windows [30]. A P $=0.05$ was considered statistically significant. A factor analysis with varimax rotation [24] was performed to condense the number of the items in the instruments and to identify factors with common characteristics. Cronbach's alpha was applied to established internal consistency. Differences in the responses between the groups were tested by the Mann-Whitney U-test [31] and the Spearman rank correlation coefficient was used to calculate the correlation between the factors.

\subsection{Ethical Considerations}

The study followed the guidelines for research set out in the Helsinki declaration [32]. The study was approved by the Head of the Institute of Nursing and the Dean of the Faculty of a University College on the east coast of Norway. In addition, the principles of confidentiality, voluntariness and informed consent were adhered to. The participants received information about the purpose of the study and indicated their consent by giving the completed consent form to their principal tutor. The data were stored in accordance with the university regulations. Permission to use the MCSS was obtained from the copyright holder, Dr. J. Winstanley (personal contact, Australia). 


\section{Results}

\subsection{Demographic Characteristics of Participants, Frequency of Sessions and Context of Supervision}

Of the 46 participants 42 were female, their mean age was 36.5 years (standard deviation (SD); range, 31.0 - 39.3) and they had 10 years of work experience (Table 1). They all had previous experience of supervision but it differed in terms of frequency, as 27 (58.6\%) had supervision daily, 14 (30.4\%) once a week, three (6.5\%) every second week and two (4.3\%) once per month during their postgraduate education. The supervision took place during work $(\mathrm{n}=27)$, in a separate room $(\mathrm{n}=2)$ and both settings $(\mathrm{n}=17)$. Furthermore, $31(70.5 \%)$ participants had individual supervision, one had group supervision and 12 (27.3\%) reported supervision in both contexts. Regarding whether the agreed supervision time was adhered to, $14(30.4 \%)$ participants answered yes, 28 (60.9\%) no and four (8.7\%) both. The time devoted to supervision per week was less than 15 minutes $(n=7), 15$ - 30 minutes $(n=11), 31-45$ minutes $(n=8), 46-60$ minutes $(n=3)$ and over 60 minutes $(n=16)$. The perception of sufficient time for supervision was reported by $23(50 \%)$ of the participants, while $23(50 \%)$ stated that it was not insufficient. Factor analysis and Cronbach's alpha coefficients of the students' $(\mathrm{N}=46)$ views on CS are presented in Table 2.

The most important factors from the MCSS regarding the need for more supervision were: Trust/Rapport, Supervisor advice and Finding time. The participants who wanted more supervision had significantly lower scores on the FESS factors: Supporting yet challenging relationship (p-value 0.004) and Preparatory and confirming professional relationship (p-value 0.002), Table 3.

\subsection{Students' Perceptions of the Quality and Effectiveness of Clinical Supervision}

To evaluate the quality and effectiveness of CS the instrument labelling and the sub-scales are described in Table 4 . This structure explained $67.3 \%$ of the variance.

\subsection{Spearman's Correlations between the Manchester Supervision Scale and Other Factors}

A highly significant association was found between Trust and Interpersonal skills $(\mathrm{P}=0.001),(r=0.50)$ as well as between Reflection, Professional and Communication skills $(\mathrm{P}=0.001),(r=0.50)$.

Furthermore, associations were found between Supervisor advice and the factors Supportive yet challenging, Preparatory and confirming professional relationship, and Interpersonal, Professional and Communications skills $(\mathrm{P}=$ $0.001),(r=0.70)$. There were no associations between Finding time and the factors: User involvement, Influence of supervision and the Effects of Supervision Scale, Table 5.

\section{Discussion}

The aim of this study was to evaluate nurse specialist students' views of CS and 
Table 2. Factor loading, Cronbach's alpha coefficients $(\alpha)$ and explained variance of the students' $(\mathrm{N}=46)$ views on clinical supervision (MCSS).

\begin{tabular}{ll}
\hline Items & Factor loading
\end{tabular}

Factor 1 Reflection

$\alpha 0.80$

Q 11 Reflection gives me time to "reflect"

Q 33 CS Improves the quality of care I give to my patients

Q 31 CS sessions motivate staff

Q 13 CS sessions facilitate reflective practice

Q 36 I think receiving clinical supervision improves the quality of care I give

Q 12 Work problems can be tackled constructively during CS sessions

Q 27 My supervisor acts in a superior manner during our sessions

Q 28 CS is for newly qualified/inexperienced staff only

Q 3 CS sessions do not solve anything

Q 7 I find supervision sessions time-consuming

Q 25 Supervision is unnecessary for experienced/established staff 
Continued

\begin{tabular}{|c|c|}
\hline Factor 6 Personal issues & \\
\hline Q 17 Having someone different to talk to about personal issues is a great help & 0.68 \\
\hline Q 18 My CS sessions are an important part of my work routine & 0.66 \\
\hline Q 21 It is important to make time for CS sessions & 0.55 \\
\hline Q 9 CS does not solve personal issues & 0.43 \\
\hline Q 5 I can 'unload' during my CS sessions & 0.42 \\
\hline Factor 7 Improved care & \\
\hline $\begin{array}{l}\text { Q } 16 \text { I can discuss sensitive issues encountered during my clinical casework } \\
\text { with my supervisor }\end{array}$ & 0.65 \\
\hline Q 8 My supervisor gives me support and encouragement & 0.62 \\
\hline Q 14 If there is something I don't understand there is always someone to ask & 0.60 \\
\hline
\end{tabular}

MCSS $=$ Manchester Clinical Supervision Scale. Cronbach alpha total $=0.80$.

its influence on their professional competence development. An additional aim was to interpret the results and link them to non-technical skills and Patient Safety (PS) topics. The research question was: What are the benefits of clinical supervision focusing on non-technical skills in the area of PS? Data were collected from 46 NSS using a package of instruments to measure the influence of CS.

CS factors that influenced the competencies of the NSS were: interpersonal, professional and communication skills, in addition to ethical skills, the importance of teamwork and awareness of the need to involve patients and their family members in safe care. Table 6 illustrates the linkages between the results of CS, non-technical skills, patient safety competencies and patient safety topics.

Despite an average of 10 years' of experience as nurses the NSS expressed the need for more CS. The NSS context is entirely different and they have new roles and functions. Their increased responsibilities give rise to a sense of insecurity. The CS of these students has traditionally focused on technical skills using a hands-on approach. There is a need to pay more attention to non-technical skills development in order to safeguard patients. CS can serve as a forum for reflection where together with their supervisor. NSS are enabled to review situations, identify what succeeded or failed and what to do on the next occasion. It is through reflection that individuals grow as professionals and develop non-technical skills [1]. The supervisors should help by challenging the behaviour of NSS in order to promote communication and teamwork skills. According to McCabe [33], nurses communicate well with patients when they use a person-centred approach. However, the ability to do so is heavily influenced by the work and culture in the organization. Interest in non-technical skills has increased in healthcare in line with the focus on increased PS to reduce the number of ad- 
Table 3. Factors, mean rank and p-value for nurses who wanted more supervision.

\begin{tabular}{|c|c|c|c|c|}
\hline Factor & $\begin{array}{l}\text { Supervision } \\
\text { frequency }\end{array}$ & $\mathrm{N}$ & Mean Rank & P-value \\
\hline \multirow{3}{*}{ Trust/Rapport } & $0 \mathrm{No}$ & 23 & 28.9 & 0.002 \\
\hline & 1 Yes & 22 & 16.7 & \\
\hline & Total & 45 & & \\
\hline \multirow{3}{*}{ Supervisor advice/support } & 0 No & 23 & 29.5 & 0.001 \\
\hline & 1 Yes & 22 & 16.2 & \\
\hline & Total & 45 & & \\
\hline \multirow{3}{*}{ Improved care } & 0 No & 22 & 23.6 & 0.776 \\
\hline & 1 Yes & 23 & 22.5 & \\
\hline & Total & 45 & & \\
\hline \multirow{3}{*}{$\begin{array}{l}\text { Importance/ } \\
\text { Value of supervision }\end{array}$} & 0 No & 22 & 20.5 & 0.306 \\
\hline & 1 Yes & 22 & 24.4 & \\
\hline & Total & 44 & & \\
\hline \multirow{3}{*}{ Finding time } & 0 No & 23 & 16.8 & 0.001 \\
\hline & 1 Yes & 23 & 30.1 & \\
\hline & Total & 46 & & \\
\hline \multirow{3}{*}{ Personal issues } & 0 No & 22 & 22.1 & 0.850 \\
\hline & 1 Yes & 22 & 22.8 & \\
\hline & Total & 44 & & \\
\hline \multirow{3}{*}{ Reflection } & 0 No & 23 & 24.9 & 0.296 \\
\hline & 1 Yes & 22 & 20.9 & \\
\hline & Total & 45 & & \\
\hline \multirow{3}{*}{$\begin{array}{l}\text { Influence supervision } \mathrm{F} 1 \\
\text { Supportive yet challenging supervision }\end{array}$} & 0 No & 23 & 28.4 & 0.004 \\
\hline & 1 Yes & 22 & 17.3 & \\
\hline & Total & 45 & & \\
\hline \multirow{3}{*}{$\begin{array}{l}\text { Influence supervision F2 } \\
\text { Preparatory and confirming } \\
\text { professional relationship }\end{array}$} & 0 No & 23 & 28.9 & 0.002 \\
\hline & 1 Yes & 22 & 16.8 & \\
\hline & Total & 45 & & \\
\hline \multirow{3}{*}{$\begin{array}{l}\text { User involvement F1/Preserving } \\
\text { integrity }\end{array}$} & $0 \mathrm{No}$ & 23 & 23.5 & 0.790 \\
\hline & 1 Yes & 22 & 22.5 & \\
\hline & Total & 45 & & \\
\hline \multirow{3}{*}{$\begin{array}{l}\text { User involvement F2/ } \\
\text { Protecting participation of } \\
\text { patients and family members }\end{array}$} & 0 No & 23 & 24.5 & 0.422 \\
\hline & 1 Yes & 22 & 21.4 & \\
\hline & Total & 45 & & \\
\hline \multirow{3}{*}{ Interpersonal skills } & 0 No & 23 & 26.8 & 0.900 \\
\hline & 1 Yes & 22 & 20.1 & \\
\hline & Total & 45 & & \\
\hline \multirow{3}{*}{ Professional skills } & 0 No & 23 & 26.2 & 0.165 \\
\hline & 1 Yes & 23 & 20.8 & \\
\hline & Total & 46 & & \\
\hline \multirow{3}{*}{ Communication skills } & 0 No & 23 & 24.9 & 0.475 \\
\hline & 1 Yes & 23 & 22.1 & \\
\hline & Total & 46 & & \\
\hline
\end{tabular}


Table 4. Included factors, Medians, Quartiles and Cronbach's alpha.

\begin{tabular}{|c|c|c|c|}
\hline Included factors & Medians & Quartiles (Q1, Q3) & Cronbach's alpha \\
\hline MCSS Trust/Rapport (15 - 35) & 29 & $(24.5,32.1)$ & 0.825 \\
\hline MCSS Supervisor advice/support (15 - 30) & 25 & $(22.0,28.0)$ & 0.783 \\
\hline MCSS Improved care/skills (16 - 35) & 28 & $(25.0,31.0)$ & 0.800 \\
\hline MCSS Importance/Value of CS (6 - 19) & 9 & $(6.0,10.8)$ & 0.777 \\
\hline MCSS Finding time (4 - 20) & 11 & $(8.0,13.0)$ & 0.737 \\
\hline MCSS Personal issues (3 - 14) & 8.5 & $(7.0,10.0)$ & 0.475 \\
\hline MCSS Reflection (5 - 15) & 12 & $(10.0,14.0)$ & 0.800 \\
\hline FESS Influence Supervision F1 (7 - 20) & 15.0 & $(12.0,17.0)$ & 0.842 \\
\hline FESS Influence Supervision F2 (4 - 12) & 9.0 & $(7.0,11.0)$ & 0.637 \\
\hline FESS User involvement F1 (4 - 16) & 14 & $(12.0,16.0)$ & 0.878 \\
\hline FESS User involvement F2 $(3-12)$ & 11 & $(9.0,12.0)$ & 0.775 \\
\hline ESS Interpersonal skills F1 (14 - 44) & 35.5 & $(31.0,39.3)$ & 0.899 \\
\hline ESS Professional skills F2 (15 - 44) & 33 & $(30.0,37.0)$ & 0.875 \\
\hline ESS Communication skills F3 (3 - 12) & 10 & $(8.0,11.0)$ & 0.828 \\
\hline
\end{tabular}

Table 5. Spearman's correlations between the MCSS and other factors.

\begin{tabular}{|c|c|c|c|c|c|c|c|}
\hline$M C S S$ & Trust/Rapport & $\begin{array}{l}\text { Supervisor } \\
\text { advice }\end{array}$ & $\begin{array}{l}\text { Improved } \\
\text { care }\end{array}$ & Importance & $\begin{array}{l}\text { Finding } \\
\text { time }\end{array}$ & $\begin{array}{l}\text { Personal } \\
\text { issues }\end{array}$ & Reflection \\
\hline \multirow{2}{*}{\multicolumn{8}{|c|}{$\begin{array}{c}\text { FESS } \\
\text { User involvement }\end{array}$}} \\
\hline & & & & & & & \\
\hline Preserving integrity & $0.373^{*}$ & $0.459^{* *}$ & 0.285 & -0.208 & -0.004 & 0.066 & $0.313^{*}$ \\
\hline $\begin{array}{c}\text { Protecting participation of } \\
\text { patients and family members }\end{array}$ & $0.349^{*}$ & $0.302^{*}$ & 0.211 & $-0.315^{\star}$ & -0.085 & -0.070 & 0.253 \\
\hline \multicolumn{8}{|l|}{ Influence of supervision } \\
\hline $\begin{array}{l}\text { Supportive yet challenging } \\
\text { relationship }\end{array}$ & $0.761^{* * *}$ & $0.765^{\star * *}$ & 0.250 & -0.067 & -0.173 & 0.205 & 0.145 \\
\hline $\begin{array}{l}\text { Preparatory and confirming } \\
\text { professional relationship }\end{array}$ & $0.596^{* * *}$ & $0.549^{* * *}$ & 0.024 & 0.019 & $-0.311^{\star}$ & 0.116 & -0.034 \\
\hline \multicolumn{8}{|l|}{ ESS } \\
\hline Interpersonal skills & $0.503^{\star * *}$ & $0.561^{\star * \star}$ & $0.353^{\star}$ & -0.073 & -0.190 & $0.401^{* *}$ & $0.373^{\star}$ \\
\hline Professional skills & $0.431^{* *}$ & $0.519^{\star \star \star}$ & $0.375^{\star}$ & -0.070 & -0.150 & $0.405^{\star *}$ & $0.500^{* * *}$ \\
\hline Communication skills & 0.249 & $0.403^{* *}$ & $0.439^{* *}$ & -0.152 & -0.098 & $0.457^{* *}$ & $0.572^{* * *}$ \\
\hline
\end{tabular}

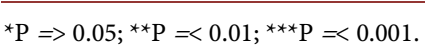


Table 6. The benefits of CS, non-technical skills, patient safety competencies and patient safety topics.

\begin{tabular}{|c|c|c|}
\hline The benefits of CS & $\begin{array}{l}\text { Non-technical skills and patient safety } \\
\text { competencies }{ }^{1,2}\end{array}$ & Patient Safety topics ${ }^{3}$ \\
\hline Interpersonal skills & Trustful relationships & Safety Culture \\
\hline Professional skills & $\begin{array}{l}\text { Self- management, situation awareness and } \\
\text { decision making }\end{array}$ & Safety Culture \\
\hline User involvement and ethical skills & Patient-centred care and responsibility & $\begin{array}{l}\text { To bring the patients' voices and experiences into the } \\
\text { patient safety agenda. }\end{array}$ \\
\hline Communication skills, reflection & Cognitive skills & Availability and transfer of appropriate knowledge. \\
\hline Teamwork & Communication, teamwork and collaboration & Safety Culture \\
\hline
\end{tabular}

1) Flin et al. [21]; 2) Rasmussen et al. [22]; 3) Jha et al. [15].

verse events [21]. De Vries et al. [19] found that $41 \%$ of all adverse events in hospitals occurred in the operating theatre. Furthermore, the authors linked these events to the failure of team cooperation [34]. According to Mc Culluch [35], reasons for the high rate of adverse events in the operating theatre are that the environment is perceived as stressful by staff and communication between team/staff members is difficult. Non-technical skills training resulted in improved attitudes to safety [35]. Professional skills on the part of NSS can be interpreted as linkages to their capacity for self-management, situational awareness and decision-making. According to Flin et al. [21], situational awareness can be explained simply as "knowing what is going around you". The terms situational awareness and situation assessment are often used synonymously. Flin et al. [21] defined situational awareness as the cognitive process for building and maintaining awareness of a workplace situation or event. The authors also described situational awareness as the first stage of decision-making, defined as the process of reaching a judgement or choosing an option, sometimes called a course of action, to meet the needs of a given situation. Elements of situational awareness can be situation assessment i.e., defining the problem, generating and considering one or more response options, selecting and implementing an option and reviewing the outcome [21]. All aspects can be seen as referring to care models such as patient-centred care and safety culture.

Despite the fact that the result of the present study revealed the importance and positive outcomes of CS for the development of PS competencies, there is still a room for improvement. The participants reported differences in the frequency of CS. Over half of the NSS stated that they were not offered enough time for CS. The participants who wanted more supervision had significantly lower scores on the factors; Supporting yet challenging and Preparatory $(\mathrm{P}=$ 0.004), confirming professional relationship $(P=0.002)$. These findings are confirmed by the study of Amsrud et al. [28] and their evaluation of undergraduate nursing students. Nursing universities are responsible for NSS programmes. In order to provide clinical supervisors with improved understanding and CS skills, the universities should devote more effort to "designing and providing" educational programmes for clinical supervisors. The supervisors must be made more 
aware of the actual importance of their supervision, particularly in terms of the development of non-technical skills. CS must be given priority in the organisation as it increases the focus on PS and safety culture. This is supported by Gordon et al. [36] who concluded that education in the use of non-technical skills can improve PS. There can be various reasons for the lack of time for CS. Clinical supervisors are usually not relieved from ordinary patient work. Finding time for CS and reflection should therefore be given high priority by management and clinical leadership. Johns [37] claims that clinical leadership is a cornerstone for the development of nursing and healthcare practice. The clinical leader is responsible for facilitating development, supporting/promoting staff competence, clinical practice and ensuring the quality of care.

\section{Limitations of the Study}

This study has some limitations. Data collection only took place on one occasion by means of the questionnaire and the sample of students was relatively small. The latter was unavoidable as the sample comprised almost all students in the class. For future research we recommend the inclusion of a larger group. The results are only valid for the study group. It would be of interest to compare different groups of students at postgraduate educational level such as master level. A mixed method design combining interviews and a questionnaire with open ended questions would be ideal for focusing on PS issues [24].

\section{Conclusion}

CS is crucial for development of non-technical skills and patient safety competencies among NSS. However, finding the time to reflect and learn from the supervisors was reported to be problematic. Thus, there is potential for quality improvement. We recommend that nursing universities should provide formal educational programmes for supervisors focusing on the students' professional development, especially non-technical skills. Management and clinical leaders should give higher priority to CS in order to enhance PS.

\section{Contributions}

The study was designed by E.S. and A.L. coordinated the research. E.R. and A.L.J. performed the data collection. E.R. and A.L.J. contributed to the study conception and literature search, supported by the specialized librarian at the university college. All authors in the research team participated in the data analysis. A.L. and E.S. were responsible for drafting the manuscript. All authors contributed to the intellectual content of the paper. The study was supervised by E.S. and A.L.

\section{Acknowledgements}

The authors wish to thank the nurse specialist students for participating in the study and Vibeke Horstmann for statistical expertise. We also thank Monique Federsel for revising the English language. This research was funded by The 
Centre for Women's, Family \& Child Health at the University College of Southeast Norway.

\section{References}

[1] Altmiller, G. (2011) Quality and Safety Education for Nurses Competencies and the Clinical Nurse Specialist Role. Implications for Preceptors. Clinical Nurse Specialist, 25, 28-32. https://doi.org/10.1097/NUR.0b013e318201f830

[2] Jokelainen, M., Turunen, H., Tossavainen, K., Jamookeeah, D. and Coco, K. (2011) A Systematic Review of Mentoring Nursing Students in Clinical Placements. Journal of Clinical Nursing, 20, 2854-2867. https://doi.org/10.1111/j.1365-2702.2010.03571.x

[3] Berggren, I. and Severinsson, E. (2011) The State of the Science of Clinical Supervision in Europe. In: Cutcliffe, J., Hyrkäs, K. and Fowler, J., Eds., Fundamental International Themes, Routledge, Milton Park, 327-337.

[4] Lyth, G. (2000) Clinical Supervision: A Concept of Analysis of Advanced Nursing. Journal of Clinical Nursing, 31, 722-729.

[5] Proctor, B. (1991) Supervision: A Co-Operative Exercise in Accountability. In: Marken, M. and Payn, M., Eds., Enabling and Ensuring. Supervision in Practice, National Bureau and Council for Education and Training in Youth and Community Work, Leicester, 21-23.

[6] Fowler, J. and Cutcliffe, J.R. (2011) Clinical Supervision. Origins, Overviews and Rudiments. In: Cutcliffe, J., Hyrkäs, K. and Fowler, J., Eds., Fundamental International Themes, Routledge, Milton Park, 8-19.

[7] Severinsson, E. (1995) Clinical Nursing Supervision in Health Care. Doctoral Dissertation, The Nordic School of Public Health, Göteborg.

[8] Kohn, L.T., Corrigan, J.M. and Donaldson, M.S. (2000) To Err Is Human: Building a Safer Health System. Committee on Quality Health Care in America, Institute of Medicine, National Academy Press, Washington DC, 6.

[9] Macchi, L., Pietikäinen, E., Reiman, T., Heikkilä, J. and Ruuhilehto, K. (2011) Patient Safety Management: Available Models and Systems. VTT, Technical Research Centre of Finland, 169.

[10] Feng, X., Bobay, K. and Weiss, M. (2008) Patient Safety Culture in Nursing: A Dimensional Concept Analysis. Journal of Advanced Nursing, 63, 310-319. https://doi.org/10.1111/j.1365-2648.2008.04728.x

[11] Mustard, L.W. (2002) The Culture of Patient Safety. Journal of Nursing Administration, Healthcare Law, Ethics and Regulation, 4, 111-115. https://doi.org/10.1097/00128488-200212000-00005

[12] Severinsson, E. (2014) Effectiveness and Implementation of Patient Safety Care. Journal of Nursing Management, 22, 823-824. https://doi.org/10.1111/jonm.12263

[13] Severinsson, E. and Holm, A.L. (2015) Patients' Role in their own Safety-A Systematic Review of Patient Involvement in Safety. Open Journal of Nursing, 5, 642-653. https://doi.org/10.4236/ojn.2015.57068

[14] Hughes, R. (2008) Patient Safety and Quality: An Evidence-Based Handbook for Nurses. Agency for Healthcare Research and Quality, Rockville.

[15] Jha, A.K., Prasopa-Plaizier, N., Larizgoitia, I. and Bates, D.W. (2010) On Behalf of the Research Priority Setting Working Group of the WHO World Alliance for Patient Safety. Patient Safety Research: An Overview of the Global Evidence. Quality Safe Health Care, 19, 42-47. https://doi.org/10.1136/qshc.2008.029165 
[16] Sullivan, T.D., Hirst, D. and Cronenwett, L. (2009) Assessing Quality and Safety Competences of Graduating Prelicensure Nursing Students. Nursing Outlook Today, 57, 323-331. https://doi.org/10.1016/j.outlook.2009.08.004

[17] Cronenwett, L., Sherwood, G., Barnsteiner, J., Disch, J., Johnson, J. and Mitchell, P. (2007) Quality and Safety Education for Nurses. Nurse Outlook, 55, 122-31. https://doi.org/10.1016/j.outlook.2007.02.006

[18] Walton, M. and Barraclough, B. (2011) Patient Safety Curriculum Guide Multi-Professional Edition. World Health Organization, Malta.

[19] De Vries E.N., Ramratten, M.A., Smorenburg, S.M., Gouma, D.J. and Boermeester M.A. (2008) The Incidence and Nature of In-Hospital Adverse Events. A Systematic Review. Quality Safety Health Care, 17, 216-223. https://doi.org/10.1136/qshc.2007.023622

[20] Leach, L.S., Myrtle, R.C., Weaver, F.A. and Dasu, S. (2009) Assessing the Performance of Surgical Teams. Health Care Management Review, 34, 29-41. https://doi.org/10.1097/01.HMR.0000342977.84307.64

[21] Flin, R., O’Connor, P. and Crichton, M. (2008) Safety at the Sharp End: A Guide to Non-Technical Skills. Ashgate Publishing Company, Burlington.

[22] Rasmussen, G., Wangen, M.G. and Torjuul, K. (2015) Ikke-tekniske ferdigheter i utøvelsen av operasjonssykepleie. Nordisk Sygeplejeforskning, 4, 397-410. (In Norwegian)

[23] Steven, A., Magnusson, C., Smith, P. and Pearson, P.H. (2014) Patient Safety in Nursing Education: Contexts, Tensions and Feeling Safe to Learn. Nurse Education Today, 34, 277-284. https://doi.org/10.1016/j.nedt.2013.04.025

[24] Polit, D.F. and Beck, C.T. (2013) Essentials of Nursing Research: Appraising Evidence for Nursing Practice. Lippincott Williams \& Wilkins, Philadelphia.

[25] Winstanley, J. (2002) Manchester Clinical Supervision Scale. Nursing Standard, 19, 31-32.

[26] Winstanley, J. (2002) Manchester Clinical Supervision Scale User Guide. Osman Consulting, Sydney.

[27] Severinsson, E. and Sand, Å. (2010) Evaluation of the Clinical Supervision and Professional Development of Student Nurses. Journal of Nursing Management, 18, 669-677. https://doi.org/10.1111/j.1365-2834.2010.01146.x

[28] Amsrud, K.E., Lyberg, A. and Severinsson, E. (2015) The Influence of Clinical Supervision and Its Potential for Enhancing Patient Safety-Undergraduate Nursing Students' Views. Journal of Nursing Education and Practice, 5, 87-95. https://doi.org/10.5430/jnep.v5n6p87

[29] Lyberg, A., Amsrud, K.E. and Severinsson, E. (2015) Evaluation Nursing Students' Views of Improved Competence Development after Clinical Supervision: An Educative Approach to the WHO Patient Safety Model. Open Journal of Nursing, 5, 725-734. https://doi.org/10.4236/ojn.2015.58075

[30] SPSS (2002) LEAD Technologies. SPSS Inc., Haddonfield.

[31] Siegel, S. and Castellan, J.N. (1998) Nonparametric Statistics for the Behavioral Sciences. McGraw-Hill Inc., New York.

[32] World Medical Association Declaration of Helsinki (2008) Ethical Principles for Medical Research Involving Human Subjects. Adopted by the 59th WMA General Assembly, Seoul. http://www.wma.net

[33] McCabe, C. (2004) Nurse-Patient Communication: An Exploration of Patients' Experiences. Journal of Clinical Nursing, 13, 41-49. 
https://doi.org/10.1111/j.1365-2702.2004.00817.x

[34] White, N. (2012) Understanding the Role of Non-Technical Skills in Patient Safety. Nursing Standard, 26, 43-48. https://doi.org/10.7748/ns.26.26.43.s53

[35] McCulloch, P., Mishra, A., Handa, A., Dale, T., Hirst, G. and Catchpole, K. (2009) The Effects of Aviation-Style Non-Technical Skills Training on Technical Performance and Outcome in the Operating Theatre. Quality and Safety in Health Care, 18, 109-115. https://doi.org/10.1136/qshc.2008.032045

[36] Gordon, M., Darbyshire, D. and Baker, P. (2012) Non-Technical Skills Training to Enhance Patient Safety: A Systematic Review. Medical Education, 46, 1042-1054. https://doi.org/10.1111/j.1365-2923.2012.04343.x

[37] Johns, C. (2003) Clinical Supervisors as a Model for Clinical Leadership. Journal of Nursing Management, 11, 25-35. https://doi.org/10.1046/j.1365-2834.2002.00288.x

Submit or recommend next manuscript to SCIRP and we will provide best service for you:

Accepting pre-submission inquiries through Email, Facebook, LinkedIn, Twitter, etc. A wide selection of journals (inclusive of 9 subjects, more than 200 journals)

Providing 24-hour high-quality service

User-friendly online submission system

Fair and swift peer-review system

Efficient typesetting and proofreading procedure

Display of the result of downloads and visits, as well as the number of cited articles Maximum dissemination of your research work

Submit your manuscript at: http://papersubmission.scirp.org/

Or contact ojn@scirp.org 